\title{
Does Pneumatosis Intestinalis after Etoposide Chemotherapy always have a Benign Course?
}

\author{
Emre Salçın, Serhad Ömercikoğlu, Serkan Emre Eroğlu, Haldun Akoğlu, Özge Onur, Arzu Denizbaşı \\ Department of Emergency Medicine, Marmara University Pendik Research and Education Hospital, İstanbul, Turkey
}

\begin{abstract}
Introduction: Pneumatosis intestinalis (PI) was reported in hematological malignancies in immunosuppressive patients who were being administered chemotherapy and steroids. However, PI generally has a benign course and is usually conservatively treated in these patients. In this case, we presented a patient who underwent chemotherapy because of testis neoplasm and was admitted to the hospital with abdominal pain, vomiting, and high blood glucose levels, and the patient died because of PI and mesenteric ischemia.

Case Report: A 38-year-old man who had type 1 diabetes mellitus and had undergone chemotherapy (bleomycin, etoposide, cisplatin, and corticosteroids) for testis neoplasm presented to the emergency room with abdominal pain. His blood glucose level was $547 \mathrm{mg} / \mathrm{dL}$. In blood gases analyses, $\mathrm{pH}=7.30, \mathrm{CHCO}=15$, and lactate $=3.2$ and ketone was positive in urine analyses. He had no specific finding on physical abdominal examination. He had undergone diabetic ketoacidosis treatment. Because his abdominal pain persisted, abdominal tomography was performed and diffuse intestinal wall necrosis and gas was observed in the portal system. He was operated and died in the intensive care unit after surgery.
\end{abstract}

Conclusion: In the emergency department, it is important to be aware of mesenteric ischemia (MI), particularly in patients who undergone chemotherapy and who were admitted to the hospital with abdominal pain. Quick and further testing for Ml is necessary.

Keywords: Pneumatosis intestinalis, mesenteric ischemia, abdominal pain, etoposide

Received: 29.06.2015 Accepted: 13.10.2015

\section{Introduction}

Pneumatosis intestinalis (PI) is the presence of gas within the wall of the intestine. It was first defined in 1783 by Du Vernoi (1). It is a critical condition and is a clinical sign rather than a disease. PI is difficult to diagnose because most patients are asymptomatic. This can be because of acute mesenteric ischemia (AMI) and subsequent bowel infarctions (2). The mortality rate of AMI is very high (3). PI is a rarely associated with the immunosuppressive status of a patient. Multidetector computed tomography (CT) is an important tool for assessing patients in the emergency room (ER). CT can provide important information regarding the cause of abdominal pain and site of ischemia if present. Conservative treatment with fasting and antibiotics can be considered in mild cases (4). However, the situation sometimes requires surgery and can be life threatening.

Lee et al (5) demonstrated that the most common causes of PI are vascular ischemia of mesentery, intestinal obstruction, and chemotherapy. The chemotherapeutics that have been reported with PI are methotrexate, daunorubicin, cytarabine, fluorouracil, paclitaxel, docetaxel, and intravenous etoposide (6). Pl due to etoposide chemotherapy are mostly benign $(6,7)$. However, in our case, we aim to show a patient who had etoposide chemotherapy because of testis neoplasm and was admitted to the hospital with abdominal pain but died because of AMI.

\section{Case Report}

A 38-year-old man who was taking chemotherapy (bleomycin, etoposide, cisplatin, and corticosteroids) for testis neoplasm and had type 1 diabetes mellitus was admitted to Emergency Room (ER) with abdominal pain, vomiting, and high blood glucose levels. He had no specific abdominal physical examination findings. His laboratory findings were White Blood Cell (WBC) count was 430 10^3 $\mathrm{LL}(\mathrm{N}=4000-10000)$, blood glucose level was 547 ( $\mathrm{N}=65-110) \mathrm{mg} / \mathrm{dL}$; and blood gas pH was 7.30 ( $\mathrm{N}=7.35-7.45)$,

\section{Address for Correspondence:}

Emre Salçın, Department of Emergency Medicine, Marmara University Pendik Research and Education Hospital, İstanbul, Turkey

E-mail: emresalcin@gmail.com

(c) Copyright 2016 by Emergency Physicians Association of Turkey - Available online at www.jemcr.org 
$\mathrm{CHCO} 3$ was $15 \mathrm{mmol} / \mathrm{L}(\mathrm{N}=21-28)$, lactate was $3.2 \mathrm{mmol} / \mathrm{L}(\mathrm{N}=0.5-$ 1.6), Na was $140(\mathrm{~N}=136-146) \mathrm{mEq} / \mathrm{L}$, and $\mathrm{Cl}$ was $106(\mathrm{~N}=98-108)$ $\mathrm{mEq} / \mathrm{L}$; therefore, the anion gap was 19 , and $2+$ ketones was detected in urine. He had undergone diabetic ketoacidosis treatment (volume replacement and insulin therapy), and because of persistent abdominal pain that was unproportional with physical signs, contrasted abdominal CT performed.

In his contrasted abdominal CT, a thrombus was observed that was $13 \mathrm{~mm}$ in diameter at the infrarenal level of the abdominal aorta and it is approximately $4 \mathrm{~cm}$ in length (Figure 1). Furthermore, a thrombus was observed at the distal part of the superior mesenteric artery. Air was present in the portal vein and portal system (Figure 2), and in all ileal segments and in cecum walls, air and necrosis was present. The diagnosis was PI secondary to chemotherapy (etoposide and corticosteroids) and AMI. His mesenteric ischemia had a "probable" association with the use of the etoposide chemotherapy based on the Naranjo score of 6 points (8).

The patient was immediately taken to surgery; however, during surgery, wide necrosis was detected in all segments of the intestines, and no viable tissue was observed in mesentery. He was admitted to the intensive care unit; however, after 3 hours, he died despite all supportive care and vasopressor therapy.

\section{Discussion}

Many etiologies for PI have been proposed; however, all of them share common concepts, a mechanical theory and an infectious theory (9). The mechanical theory is widely accepted. A break in the intestinal mucosa permits air to pass, and under pressure, gases in the lumen invade the submucosa. Although PI may occur in the absence of the primary disorder, it is usually associated with intestinal obstruction, perforation, inflammation, ulceration, diverticula, tumors, or chemoradiotherapy in malignancies (9), as in our case and organ transplantation under immunosuppression.

When observed in the small intestine, PI is frequently presented with vomiting, weight loss, abdominal distension, and discomfort; in contrast, when PI is observed in large intestinal segments, it is frequently presented with diarrhea and hematochezia. In our patient, the most marked symptoms was vomiting, abdominal distension, and discomfort.

PI can also be observed in patients who had chemotherapy. Myelosuppressive agents induce bone marrow suppression and granulocytopenia because intestinal mucosa is highly proliferative, and it is supposed that mucosal damage easily occurs under chemotherapy (7). Combined chemotherapy, including corticosteroids, may induce an atrophy of Payer's patches in the intestine (7), resulting in mucosal defects and lowering immune defense mechanism. Several chemotherapeutic agents have been reported to be associated with $\mathrm{Pl}$, including methotrexate, daunorubicin, cytarabine, fluorouracil, paclitaxel, docetaxel, and intravenous etoposide, as in our case $(6,9,10)$. The Naranjo algorithm is an inquiry designed by Naranjo et al (8) for determining the likelihood of whether an adverse drug reaction is actually due to the drug rather than the results of other factors. Probability is assigned possible or doubtful. Therefore, we found that our case has a "probable" association

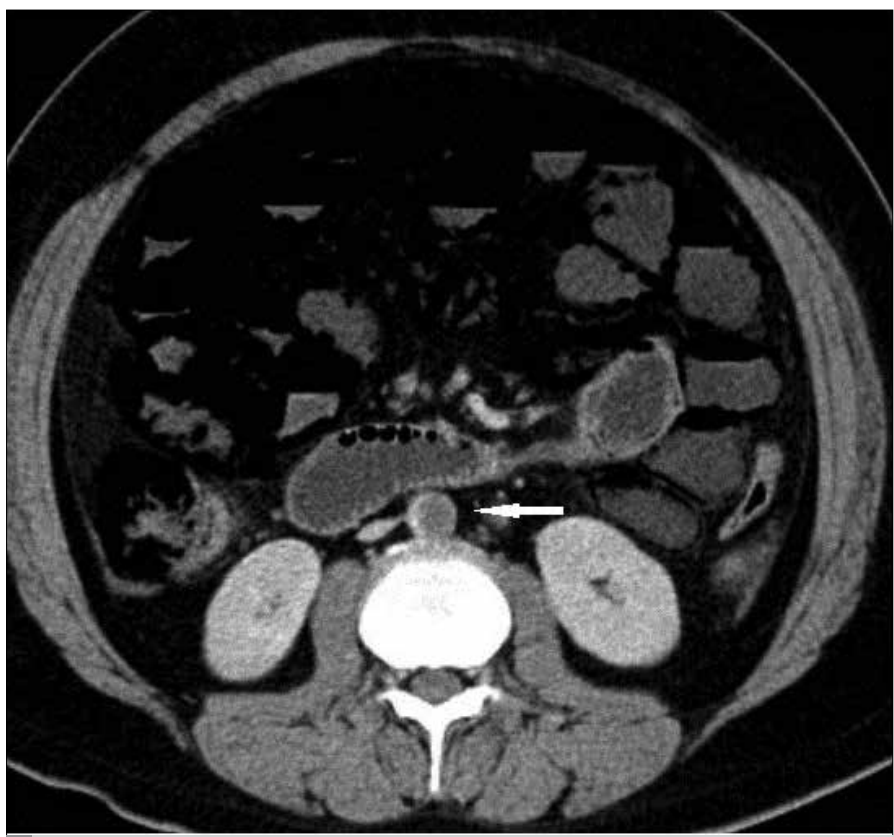

Figure 1. Thrombus that is $13 \mathrm{~mm}$ in diameter at the abdominal aorta's infrarenal level and $4 \mathrm{~cm}$ in length

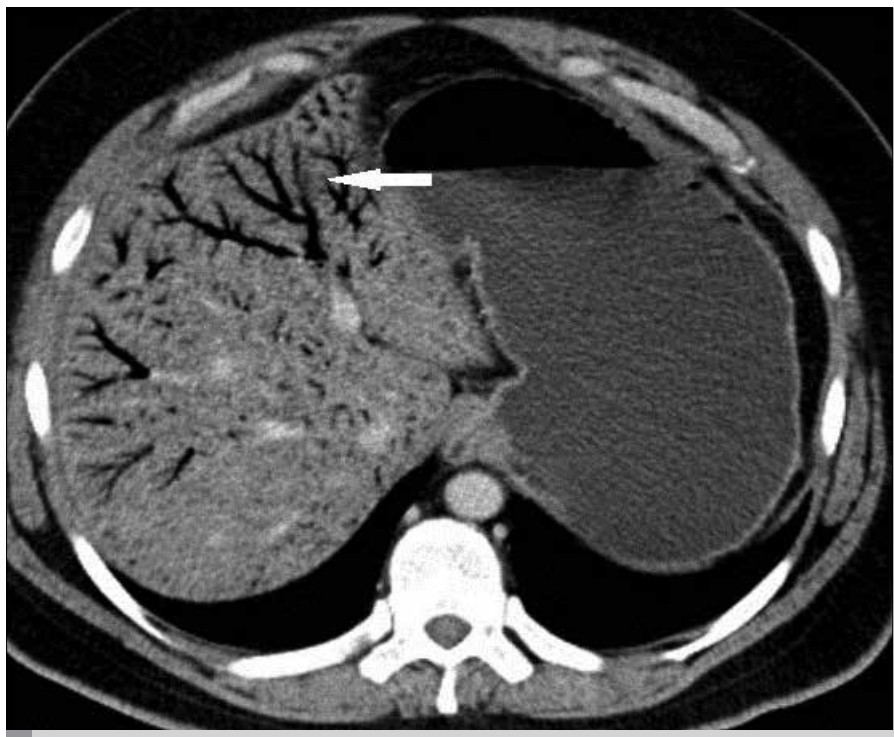

Figure 2. Air in portal vein and portal system

with etoposide chemotherapy. In one case report, PI had been observed after etoposide chemotherapy for breast cancer (6). In another case series, PI was observed in three patients who had etoposide therapy because of their hematological malignancies, and all these patients had a benign course (7). However, our patient had mesenteric ischemia and died.

\section{Conclusion}

In ER, it is important to be aware of mesenteric ischemia, particularly in patients who had undergone chemotherapy and who were admitted to the hospital with abdominal pain. If there is any suspicion regarding mesenteric ischemia, all diagnostic tests and radiological imaging must be immediately performed. It may have a catastrophic end. 
Informed Consent: Written informed consent could not be taken, because the patient who was mentioned in the text had already been deceased.

Peer-review: Externally peer-reviewed.

Author contributions: Concept - E. S., S. Ö.; Design - E. S.; Supervision - S. E. E., Ö. O.; Resource - H. A., A. D.; Data Collection and/or Processing - E. S., S. E. E.; Analysis and/or Interpretation - S.Ö., Ö. O.; Literature Search - E. S., H. A.; Writing - E. S., S. E. E.; Critical Reviews - Ö. O., A. D.

Conflict of Interest: The authors declared no conflict of interest.

Financial Disclosure: The authors declared that this study has received no financial support.

\section{References}

1. Heng Y, Schuffler MD, Haggit RC, Rohrmann CA. Pneumatosis intetinalis: a review. Am J Gastroenterol 1995; 90: 1747-58

2. Ernest D, Schneiderman D. Other diseases of the colon and rectum. In: Gastrointestinal Disease: Pathophysiology, Diagnosis, and Management. Sleisenger MH, Fodtran JS, Eds. Harcourt Brace Jonanovich, Philadelphia: 1989. p. 1595.
3. Kortmann B, Klar E. Recognizing acute mesenteric ischaemia too late: reasons and diagnostic approach from a surgical point of view. Zentralbl Chir 2005; 130: 223-6. [CrossRef]

4. Karabuga T, Yoldas O, Ozsan I, Yıldırım UM, Aydin U. Diagnostic laparoscopy for pneumatosis intestinalis: to do or not to do? Am J Emerg Med 2014; 32: 1555. [CrossRef]

5. Lee HS, Cho YW, Kim KJ, Lee JS, Lee SS, Yang SK. A simple score for predicting mortality in patients with pneumatosis intestinalis. Eur J Radiol. 2014; 83: 639-45. [CrossRef]

6. Shih IL, Lu YS, Wang HP, Liu KL. Pneumatosis coli after etoposide chemotheraphy for breast cancer. J Clin Oncol. 2007; 25: 1623-5. [CrossRef]

7. Hashimoto S, Saitoh H, Wada K, Kobayashi T, Furushima H, Kawai H, et al. Pneumatosis cystoides intestinalis after chemotherapy for hematological malignancies: report of 4 cases. Intern Med. 1995; 34: 212-5. [CrossRef]

8. Naranjo CA, Busto U, Sellers EM, Sandor P, Ruiz I, Roberts EA, et al. A method for estimating the probability of adverse drug reactions. Clin Pharmacol Ther. 1981; 30: 239-45. [CrossRef]

9. Priest E, Goldstein F. Pneumatosis cystoides intestinalis. In: Gastroenterology, Berk JE, Ed. WBSaunders, Philadelphia: 1985. p. 2474.

10. Candelaria M, Bourlon-Cuellar R, Zubieta JL, Noel-Ettiene LM, SanchezSanchez JM. Gastrointestinal pneumatosis after docetaxel chemotherapy. J Clin Gastroenterol. 2002; 34: 444-5. [CrossRef] 